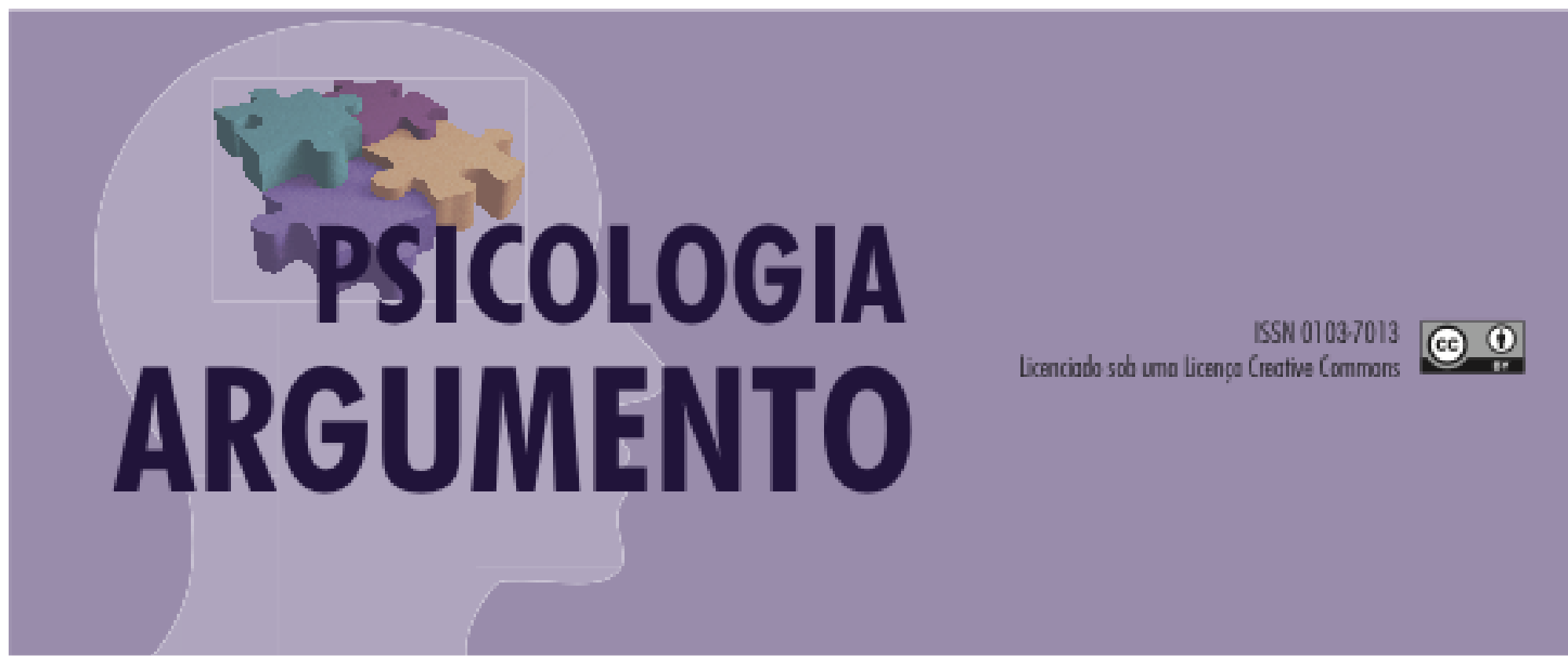

doi: http://dx.doi.org/10.7213/psicolargum.38.99.AO02

\title{
A Educação Inclusiva e os Transtornos Específicos de Aprendizagem: em foco a Dislexia.
}

\section{Inclusive Education and Specific Learning Disorders: focus on Dyslexia}

Educación inclusiva y trastornos específicos del aprendizaje: en foco Dislexia

\author{
Drieli Rafagnin \\ Pedagoga UNIOESTE Campus Cascavel PR, e-mail drika_rafagnin@hotmail.com \\ ORCID: 0000-0002-3398-6473
}

Maria Ester Rodrigues

Doutora em Psicologia da Educação PUC SP, Profa. UNIOESTE Campus Cascavel PR, e-mail mariaester.rodrigues@gmail.com ORCID: 0000-0002-6316-1552

Paula Emanuele Bello Kosloski

Pedagoga pela UNIOESTE Campus Cascavel PR, Mestranda em Educação PPGE Campus Cascavel PR e-mail paulla.emanuele@gmail.com Orcid: 0000-0001-7253-0295

Este trabalho é um ensaio sobre educação inclusiva dislexia, apoiando-se em leis e referenciais teóricos. Justificase esta discussão pela constatação de que a educação inclusiva ainda não é uma realidade plenamente efetivada em nossas escolas por várias razões. Assim, apresentamos a base legal vigente da inclusão de alunos disléxicos no ensino regular; as principais intervenções pedagógicas apropriadas; a definição e as características da dislexia; as principais adaptações recomendadas em sala de aula, incluindo as avaliativas e a confecção e a execução do Plano de Ensino Individual (PEI) ou Plano de Desenvolvimento Individual (PDI). A principal conclusão é a de que as escolas devem seguir as leis que garantem a inclusão de alunos com Necessidades Educacionais Especiais (NEEs) em salas regulares de ensino por meio da confecção e da execução do PEI dos alunos, de acordo com as suas necessidades, e da utilização de métodos de alfabetização apropriados em larga escala, que favoreçam tanto alunos disléxicos quanto crianças neurotípicas.

Palavras-chave: Dislexia, Educação Inclusiva, Necessidades Educacionais Especiais, Plano de Ensino Individualizado. 


\begin{abstract}
This work is an essay on inclusive dyslexia education, based on laws and theoretical frameworks. This discussion is justified by the fact that inclusive education is not yet a reality fully implemented in our schools for several reasons. Thus, we present the current legal basis for the inclusion of dyslexic students in regular education; the main appropriate pedagogical interventions; the definition and characteristics of dyslexia; the main adaptations recommended in the classroom, including evaluations and the preparation and execution of the Individual Education Plan (PEI) or Individual Development Plan (PDI). The main conclusion is that schools must follow the laws that guarantee the inclusion of students with Special Educational Needs (NEEs) in regular teaching rooms through the preparation and execution of the students' PEI, according to their needs, and the use of appropriate large-scale literacy methods that favor both dyslexic students and neurotypical children
\end{abstract}

Keywords: Dyslexia, Inclusive Education, Special Educational Needs, Individualized teaching plan.

\title{
Resumen
}

Este trabajo es un ensayo sobre educación dislexia inclusiva, basado en leyes y marcos teóricos. Esta discusión se justifica por el hecho de que la educación inclusiva aún no es una realidad plenamente implementada en nuestras escuelas por varias razones. Por lo tanto, presentamos la base legal actual para la inclusión de estudiantes disléxicos en la educación regular; las principales intervenciones pedagógicas apropiadas; la definición y características de la dislexia; Las principales adaptaciones recomendadas en el aula, incluidas las evaluaciones y la preparación y ejecución del Plan de Educación Individual (PEI) o el Plan de Desarrollo Individual (PDI). La conclusión principal es que las escuelas deben seguir las leyes que garantizan la inclusión de los estudiantes con necesidades educativas especiales (NEE) en las aulas de enseñanza regulares a través de la preparación y ejecución del PEI de los estudiantes, de acuerdo con sus necesidades, y el uso de métodos apropiados de alfabetización a gran escala que favorecen tanto a los estudiantes disléxicos como a los niños neurotípicos.

Palabras clave: Dislexia, Educación Inclusiva, Necesidades Educativas Especiales, Plan de Enseñanza Individualizado.

\section{Introdução}

O presente trabalho é um ensaio sobre educação inclusiva e dislexia (transtorno específico de aprendizagem com prejuízo em leitura). Iniciamos apresentando a legislação que atende ao aluno disléxico de forma inclusiva em sala de aula regular, desde os tratados internacionais dos quais o Brasil é signatário e que inspiraram a criação de leis inclusivas na educação, a Declaração Mundial sobre Educação para TODOS (United Nations Children's Fundation - UNICEF 1990), a Declaração de Salamanca (United Nations Educational, Scientific and Cultural Organization, UNESCO 1994), até as leis propriamente ditas que garantem a educação inclusiva dentro do Brasil, tais como a Constituição, a maior de todas (Constituição da República Federativa do Brasil, 1988), a Lei de Diretrizes e Bases (LDB) (Lei $\mathrm{n}^{\circ}$ 9.394, 1996) e o Estatuto da Criança e do Adolescente (ECA) (Lei $\mathrm{n}^{\circ}$ 8.069, 1990). Apresentamos a diferenciação entre educação inclusiva e educação especial e as suas bases legais, bem como intervenções pedagógicas para alunos com necessidades educacionais especiais (NEEs, doravante). Além disso, também apresentamos informações acerca de um 
projeto de lei (Projeto de lei $n^{\circ} 7081,2010$ ) específico para o atendimento da dislexia e do Transtorno do Déficit de Atenção com Hiperatividade (TDAH, deste ponto em diante).

Em seguida, apresentamos o conceito de dislexia, as suas características, as adaptações curriculares apropriadas ao aluno disléxico (principalmente em procedimentos avaliativos), o método de alfabetização, bem como as noções de elaboração e de execução do Plano de Ensino Individual (PEI, de ora em diante) do aluno. Por fim, as considerações finais.

Consideramos necessário partir da leitura e da organização de leis e artigos científicos que versassem sobre as temáticas: Educação Inclusiva, Educação Especial, Dislexia, Inclusão, Plano de Desenvolvimento Individual e Adaptações Curriculares. A escolha das leituras foi realizada a partir da procura em bases de dados, privilegiando-se a literatura de referência na área e material encontrado em sites de associações nacionais e internacionais dedicadas ao tema.

\section{Tratados internacionais e Base legal educacional inclusiva}

A primeira vez em que se falou em educação inclusiva foi na década de 1990, apoiandose nos tratados internacionais dos quais o Brasil é signatário, tais como: a Declaração Mundial sobre Educação para TODOS (UNICEF 1990) e a Declaração de Salamanca (UNESCO 1994). O primeiro documento estipula a Educação para TODOS, sem exceções. Em seu terceiro artigo, defende a Universalização do acesso à educação e a promoção da equidade, com redução de desigualdades sem ferir a qualidade; no artigo quarto, por sua vez, temos a concentração de atenção na aprendizagem e no desenvolvimento efetivos.

A Declaração de Salamanca (UNESCO, 1994) sugere maior atenção a crianças com NEEs e fala, pela primeira vez, mundialmente, em educação inclusiva, enfatizando a matrícula no ensino regular de todas as crianças, independente das dificuldades que apresentem, e incentivando o aprimoramento dos sistemas educacionais para que as recebam.

Além desses documentos internacionais, a Constituição Federal (Constituição da República Federativa do Brasil, 1988) compreende, no Capítulo III, seção I, artigo 205, a educação como direito de todos, a ser oferecida pelo estado, promovida e incentivada pela família e pela sociedade.

Assim como a Constituição Federal (Constituição da República Federativa do Brasil de 1988), a Lei de Diretrizes e Bases da Educação Nacional (LDBEN), de 20 de dezembro de 1996, estabelece a inclusão de crianças com NEEs nas escolas regulares de ensino, com assistência, garantindo a educação para todos no sistema regular de ensino. A mesma lei, no artigo $13^{\circ}$, oferece autonomia à escola, à direção, à coordenação e aos professores para intervirem pedagogicamente a fim de garantir o ensino do aluno com NEEs. No terceiro artigo da mesma lei, destaca-se que: "Art. $3^{\circ}$. O ensino será ministrado com base nos seguintes princípios: I - igualdade de condições para o acesso e permanência na escola [...] Art. $4^{\circ}$. [...] - 
atendimento educacional especializado gratuito aos educandos com necessidades especiais, preferencialmente na rede regular de ensino[...]" (Lei no 9.394, 1996, pp. 1-2).

Ainda no que diz respeito aos dispositivos legais nacionais, o Estatuto da Criança e do Adolescente - ECA - $\left(\right.$ Lei $\left.n^{\circ} 8.069,1990\right)$ também garante a todas as crianças o acesso e a permanência na escola, entre outros direitos, com foco em seu desenvolvimento integral.

Em consonância com o ECA (Lei no 8.069, 1990) e a LDBEN (Lei $\left.{ }^{\circ} 9.394,1996\right)$, as Diretrizes Nacionais para a Educação Especial na Educação Básica (Resolução CNE/CEB nº 2, 2001) determinam que todos os alunos com NEEs devem ser matriculados e acompanhados em todas as etapas e modalidades da Educação Básica (Educação Infantil, Ensino fundamental I e II e Ensino Médio), nos artigos primeiro e segundo.

As NEEs referem-se às dificuldades encontradas por alunos que precisam de apoio educacional especial em algum momento de seu percurso escolar, independente das razões, sejam advindas de deficiência, de transtorno ou não. As NEEs devem resultar na diferenciação do atendimento oferecido ao aluno, conforme esclarece a Declaração de Salamanca (UNESCO, 1994).

Um aluno com transtornos de aprendizagem pode ser considerado um aluno com NEEs, bem como vários outros alunos portadores de condições diagnósticas permanentes (ou não). Alunos sem transtornos permanentes também podem apresentar NEEs em algum momento de sua vida escolar, como uma aluna gestante ou um aluno com dificuldade em um conteúdo particular, por razões variadas.

Os tratados internacionais dos quais o Brasil é signatário e as leis brasileiras que tratam da educação inclusiva garantem o atendimento a alunos com NEEs em geral, não tratando especificamente de nenhum diagnóstico em particular. Tais leis direcionam a escola em busca de recursos apropriados para o cumprimento das necessidades de cada aluno, sem depender de um laudo para que o atendimento de suas necessidades educacionais especiais ocorra. Já o art. 59 da LDBEN, que trata da legislação específica da educação especial, prevê que apenas alunos com deficiências, transtornos globais do desenvolvimento e altas habilidades ou superdotação sejam atendidos pelos sistemas da educação especial: "Art. 59. Os sistemas de ensino assegurarão aos educandos com deficiência, transtornos globais do desenvolvimento e altas habilidades ou superdotação: I. currículos, métodos, técnicas, recursos educativos e organização específicos, para atender às suas necessidades [...]" (Lei no 9.394, 1996, p. 19). O Plano Nacional de Educação para a Educação Especial (Lei nº 13.005, 2014) prevê diagnósticos semelhantes aos contidos no texto da LDBEN, restringindo o atendimento ou entendendo como 
NEEs apenas as originadas por deficiências (física, sensorial, mental ou múltipla) ou por características como altas habilidades, superdotação ou talentos.

A partir desse resgate das leis referentes ao atendimento ao aluno disléxico (educação inclusiva), podemos destacar que a educação especial e a educação inclusiva não podem ser entendidas como sinônimos. A educação especial é uma modalidade da educação escolar que perpassa transversalmente todos os níveis e etapas de ensino, utilizando-se de ferramentas didáticas que auxiliam a criança na compreensão e no atendimento de suas diversas necessidades. Nessa direção, existe o Atendimento Educacional Especializado (AEE, doravante), que consiste no atendimento realizado com o aluno, preferencialmente dentro da escola regular ou em Centros de AEE, caso a escola regular não tenha um espaço como uma sala de Recursos Multifuncional tipo $\mathrm{I}^{1}$ para atendimento. É válido lembrar que o AEE é um atendimento pedagógico, não é atendimento psicológico, neurológico, fonoaudiológico ou com outros profissionais extraescolares. $\mathrm{O}$ aluno frequenta o AEE no contraturno escolar.

A educação inclusiva, por sua vez, pretende atender a todos os que, transitória ou permanentemente, apresentem NEEs, bem como grupos minoritários da população. A educação inclusiva é, segundo Sousa (2018), muito mais ampla e atende a toda a população, enquanto a educação especial é uma modalidade de ensino que oferece AEE.

O Projeto de Lei $n^{\circ} 7.081 / 2010$ foi criado pelo Senador Federal Gerson Camata, em 2010, tratando especificamente da Dislexia (Transtorno específico de aprendizagem) e do TDAH e está sob a relatoria atual do Deputado Rubens Bueno. O Projeto foi aprovado na Câmara no dia 07 de novembro de 2018 e ainda necessita de aprovação do Senado e de sancionamento da Presidência da República para vigorar. A expectativa é que facilite a identificação e o atendimento às crianças portadoras de Dislexia e/ou TDAH.

\section{Intervenções pedagógicas para alunos com necessidades educativas especiais (NEEs)}

As adaptações curriculares referem-se aos procedimentos pedagógicos utilizados pelo professor para atender às necessidades individuais dos alunos. A depender de cada criança e de suas NEEs, respostas educativas especiais devem ser fornecidas. O professor deve estabelecer objetivos, identificar as habilidades dos alunos, os pré-requisitos existentes (ou não) para a

\footnotetext{
${ }^{1}$ Dutra, Santos e Guedes (2010) diferenciam as salas de recursos de tipo I e de tipo II, sendo elas: "A escola de ensino regular deve ter matrícula de aluno(s) público alvo da educação especial em classe comum, registrado(s) no Censo Escolar/INEP, para a implantação da sala Tipo I" (p. 10) e do tipo II atende alunos com deficiência visual "A escola de ensino regular deve ter matrícula de aluno(s) cego(s) em classe comum, registrado(s) no Censo Escolar/INEP, para a implantação da sala de Tipo II." (Dutra, Santos, \& Guedes, 2010, p. 10).
} 
consecução dos objetivos, escolher procedimentos de ensino, dividir o conteúdo em partes mais fragmentadas, ou apenas reapresentar o conteúdo para que o aluno o entenda, para, posteriormente, seguir para o próximo. A escolha de materiais, de recursos, de métodos e de procedimentos/critérios de avaliação também fazem parte das respostas educativas a serem fornecidas (Rodrigues, 2015). O professor tem autonomia em sala de aula para usar a metodologia/estratégia de ensino que seja melhor para a turma e para alunos particulares, utilizando-se de diferentes estratégias de ensino e fazendo uso de tecnologias disponíveis na escola.

Quanto às adaptações curriculares a serem realizadas, ressalta-se que as crianças devem ter suas necessidades adaptadas aos programas de ensino, e no que se refere às crianças com necessidades educativas especiais, é imprescindível o apoio adicional no programa regular de estudo (Parâmetros Curriculares Nacionais: Adaptações curriculares, 1998). As adaptações curriculares referem-se, ainda, às diversas maneiras como o professor pode atuar e diversificar o ensino de acordo com a necessidade do aluno, intervindo pedagogicamente da maneira que melhor se encaixe na necessidade educacional especial específica que o seu aluno apresenta.

Algumas adaptações importantes a serem realizadas são, segundo os Parâmetros Curriculares Nacionais: Adaptações curriculares (1998) e Heredero (2010), adequações em objetivos, conteúdos, metodologias e critérios de avaliação. Existem adaptações de pequeno porte e de grande porte. Para os Parâmetros Curriculares Nacionais: Adaptações curriculares (1998) as adaptações curriculares de pequeno porte são implantadas e dirigidas pelo professor, logo, não dependem de instâncias superiores (âmbito político, administrativo e/ou técnico) para serem executadas.

Segundo Leite (2008) as adaptações curriculares de grande porte são adaptações estruturais, as quais não dependem apenas do professor, necessitando da autorização de instâncias superiores nas áreas política, técnica e administrativa escolar e extraescolar (Projeto Político Pedagógico - doravante PPP da escola -, Núcleo Regional de Educação - doravante NRE - etc.).

Os objetivos de ensino podem ser priorizados ou mesmo modificados pelo professor. Os Parâmetros Curriculares Nacionais: Adaptações curriculares (1998) mencionam a priorização de objetivos de acordo com as necessidades educacionais de um aluno, o investimento em estratégias pedagógicas e tempo com a finalidade de garantir o acesso e a permanência de todos na escola. Como exemplo podemos mencionar o aluno em série avançada ainda não alfabetizado, caso em que o objetivo adicional de alfabetizar obviamente deve ser acrescido. 
Isso se ele tiver repertório para ser alfabetizado, saiba falar e nomear objetos, por exemplo. Caso contrário, habilidades tidas como pré-requisito para a alfabetização terão que ser instaladas, como o ensino da fala.

O Plano de Desenvolvimento Individual (PDI, deste ponto em diante), segundo Sousa (2018), é um dever que a instituição escolar tem, por se tratar de uma regulamentação da união em consonância com a base legal inclusiva anteriormente apresentada e com os ditames internacionais dos quais o Brasil é signatário. Esse planejamento promove a igualdade de oportunidades de aprendizado.

Segundo Poker, Martins, Oliveira, Milanez e Girotto (2013) o PDI analisa e aponta as condições do aluno para ter acesso ao currículo da série em que se encontra, envolvendo o espaço da escola, os materiais, os recursos disponíveis, as estratégias utilizadas pelo professor, o envolvimento da família do aluno, bem como as suas condições específicas para aprender.

Redig, Mascaro, \& Dutra (2017) e Sousa (2018) declaram que a elaboração de um PDI ampara o professor em todo o processo de intervenção pedagógica, auxiliando-o na identificação das dificuldades e do progresso de cada aluno em curtos períodos. Para Poker et al. (2013), o PDI é “[...] um mecanismo em construção contínua e passível de revisões e adaptações devendo ajustar-se às necessidades de cada rede de ensino, de cada escola, de cada professor e, principalmente, da realidade e das necessidades educacionais de cada aluno" (p. $13)$.

O PDI é composto, via de regra, de informações sobre o aluno, incluindo avaliações pedagógicas e psicopedagógicas e, na segunda parte, de elaboração da intervenção pedagógica especializada que irá listar as ações necessárias (e os responsáveis pelas ações) para atender às suas necessidades educacionais especiais, os recursos e os responsáveis, bem como os prazos previstos.

O PDI também é conhecimento como Plano de ensino individual (PEI) por alguns autores, e é muito importante, pois se torna, quando realizado corretamente, um guia para o próprio professor e para outros professores que trabalhem ou venham a trabalhar com a mesma criança, possibilitando ter um histórico mais detalhado de sua vida escolar. Ademais, favorece a realização das adaptações curriculares (de pequeno ou grande porte) necessárias, a partir da necessidade de cada aluno. Essas adaptações, segundo Leite (2008), podem ser realizadas em dois níveis: "no nível coletivo (sala de aula), por meio do planejamento e implementação do currículo da classe, e no nível individual, por meio do programa educacional individualizado [grifo nosso] (PEI)" (p. 19). 


\section{A Dislexia e a Inclusão do aluno disléxico}

Segundo a American Psychiatric Association (APA, 2014), a dislexia é um transtorno específico de aprendizagem, um tipo de transtorno do neurodesenvolvimento que compromete a capacidade para aprender habilidades acadêmicas específicas (de leitura, de escrita ou de matemática), que são a base de outras competências acadêmicas. O termo dislexia é sinônimo ou termo alternativo utilizado em referência ao transtorno específico de aprendizagem com prejuízo na leitura, assim como discalculia é sinônimo de transtorno de aprendizagem com prejuízo na matemática e a disgrafia pode ser considerada transtorno de aprendizagem com prejuízo na escrita. Conforme o Manual Diagnóstico e Estatístico de Transtornos Mentais, publicado por essa associação, a "Dislexia é um termo alternativo usado em referência a um padrão de dificuldades de aprendizagem caracterizado por problemas no reconhecimento preciso ou fluente de palavras, problemas de decodificação e dificuldades de ortografia [...]" (APA, 2014, p. 67).

Os critérios de diagnóstico dos transtornos específicos de aprendizagem, os mesmos da dislexia, são quatro (A, B, C, D e E) e, segundo a APA (2014), todos devem ser atendidos. Quando mais de um domínio estiver prejudicado, codifica-se cada um individualmente, especificando-se com prejuízo na leitura, na expressão escrita ou na matemática.

Pelo critério A, verifica-se a existência de pelo menos um conjunto de características relativamente duradouro, mesmo após intervenção séria e baseada em evidências (APA, 2014). As características-chave dos transtornos específicos de aprendizagem, embutidos no critério A de diagnóstico do DSM-V (APA, 2014), nos quais a dislexia se inclui, são a persistência de dificuldades de decodificação, de compreensão, de ortografia, de expressão escrita, de cálculo ou de raciocínio, por pelo menos seis meses, mesmo após intervenções extras e instruções específicas. O critério B preconiza que as habilidades acadêmicas devem estar substancialmente afetadas para a idade e nível acadêmico e interferir negativamente no desempenho do indivíduo (acadêmico ou no trabalho), o que deve ser confirmado por testes padronizados e avaliação clínica abrangente (APA, 2014).

O critério C enfatiza a necessidade de o transtorno ter se iniciado nos anos escolares, ou seja, não tem início nem na adolescência e nem na vida adulta. Já o critério D de diagnóstico apresenta claramente um elemento de descarte para o diagnóstico (ou diagnóstico diferencial) 
de transtorno de aprendizagem, que é a presença de diagnóstico de deficiência intelectual, deficiências sensoriais e outros diagnósticos diferenciais: "As dificuldades de aprendizagem não podem ser explicadas por deficiências intelectuais, acuidade visual ou auditiva não corrigida, outros transtornos mentais ou neurológicos, adversidade psicossocial, falta de proficiência na língua de instrução acadêmica ou instrução educacional inadequada" (APA, 2014, p. 67).

A International Dyslexia Association (IDA, 2002), define dislexia como uma disfunção neurobiológica caracterizada pela dificuldade no reconhecimento e na decodificação das palavras. A Associação Brasileira de Dislexia (ABD) e o National Institute of Child Health and Human Development (NICHD) também utilizam a definição da IDA, qual seja:

A dislexia é um distúrbio específico de aprendizagem de origem neurológica. É caracterizada por dificuldades no reconhecimento de palavras preciso e/ou fluente e por distúrbios na capacidade de ortografia e decodificação. Essas dificuldades tipicamente resultam de um déficit no componente fonológico da linguagem que é muitas vezes inesperado em relação a outras habilidades cognitivas e à provisão de instrução efetiva em sala de aula. Consequências secundárias podem incluir problemas de compreensão de leitura e redução da experiência de leitura que podem impedir o crescimento do vocabulário e do conhecimento prévio. (IDA, 2017. p. 4, tradução nossa).

As causas da dislexia, segundo a IDA (2017), são neurobiológicas (cérebro diferente em desenvolvimento e funcionamento) e hereditárias. Segundo Luca e Nico (2018), existem alterações neurobiológicas, comportamentais e funcionais importantes na dislexia, muito embora os déficits não se apresentem todos na mesma intensidade em todos os indivíduos. A literatura científica não fala em diferenças de gênero entre disléxicos; no entanto, a ABD (2018) recebe maior demanda para avaliação de meninos, talvez por serem percebidos com maior facilidade em sala de aula. Luca e Nico (2018) e Rodrigues (2018) mencionam que as meninas fazem processamento de linguagem nos dois hemisférios (direito e esquerdo), enquanto os meninos utilizam apenas o hemisfério esquerdo (o mais prejudicado na dislexia). Portanto, meninas disléxicas fazem a compensação entre os dois hemisférios e são percebidas apenas no ensino médio ou superior, etapa em que suas habilidades acadêmicas são mais exigidas; os meninos, por sua vez, são identificados mais facilmente ainda em fase de alfabetização.

Entre as características do disléxico, a principal é a dificuldade no estabelecimento da relação fonológica (relação letra-som). Por isso, há a dificuldade da criança e de adultos disléxicos, principalmente os que não foram devidamente ensinados, em reconhecer palavras, decodificá-las e escrevê-las. Línguas com baixa relação letra-som (como o inglês) apresentam dificuldades muito maiores para aquisição por indivíduos disléxicos do que línguas com alta relação letra-som, como o finlandês (Capellini, Germano, \& Cardoso, 2008; Barbosa, 
Rodrigues, Toledo-Piza, Navas, \& Bueno, 2015; Silva \& Capellini, 2015; Matta, Perrut, \& Alcântara, 2017; Luca \& Nico, 2018).

Uma segunda característica muito importante são as diferenças no processamento visual e/ou auditivo, o que não equivale a ter problemas sensoriais ou deficiência auditiva e visual propriamente dita. A depender do tipo de alteração ou combinação de alterações, a dislexia irá se manifestar de modo diferenciado em cada indivíduo (Capellini et al., 2008; Lima, Salgado, \& Ciasca, 2008; Barbosa et al., 2015; Luca \& Nico, 2018).

A terceira característica mais importante é o prejuízo na memória imediata (Barbosa et al., 2015; Luca \& Nico, 2018). Em outras palavras, os disléxicos terão dificuldade para decorar coisas, para memorizar sequências em geral (como a tabuada e o alfabeto), farão roteiros próprios de memorização, precisarão de dicas para resolução de problemas, apresentarão disnomias e dificuldade para nomear lateralidade ${ }^{2}$.

$\mathrm{Na}$ idade escolar, a principal alteração comportamental do disléxico é a dificuldade na aquisição e na automação da leitura e o medo de ler em voz alta, principalmente para quem não foi alfabetizado por métodos fônicos ou fonológicos. Tais métodos propiciam o reconhecimento de sons e a montagem de novas palavras e da consciência fonológica propriamente dita. Já os métodos do tipo "global" não propiciam o estabelecimento de tais habilidades, básicas para a instalação da leitura (Muszkat \& Rizzutti, 2012; Fonseca, 2017). Existem igualmente dificuldades severas com a escrita, uma vez que a leitura é pré-requisito para a escrita e quem não lê não escreve.

Como características gerais, o disléxico em idade escolar é lento com as atividades escolares, tende a não completar as tarefas em sala de aula, não gosta de realizar tarefas de casa (pelas dificuldades envolvidas), pode ter dificuldades com esportes coletivos (coordenação motora grossa prejudicada, além da fina), costuma ser mais literal e ter dificuldades para compreender piadas e mensagens de duplo sentido (Muszkat \& Rizzutti, 2012; Lemos, 2016; Luca \& Nico, 2018).

Além disso, esse aluno pode apresentar dificuldades com matemática ou não, mas, com idiomas estrangeiros, a dificuldade já existente em sua primeira língua se acentua, especialmente no que se refere ao domínio do código escrito (Luca \& Nico, 2018). Não se recomenda que crianças de risco ou já diagnosticadas, em fase de alfabetização, sejam

\footnotetext{
2 É comum apresentarem lateralidade mista ou cruzada.
} 
submetidas ao ensino de língua estrangeira por métodos convencionais (Comunidade Aprender Criança/Instituto Glia, 2014).

Apesar da literatura em geral enfatizar os aspectos negativos, os disléxicos também apresentam características positivas. Luca e Nico (2018) mencionam que eles são inteligentes, criativos e têm qualidades bastante competitivas em um mercado de trabalho inovador (National Aeronautics and Space Administration - NASA, APPLE) e repleto de desafios, por terem uma visão de problemas por diferentes perspectivas e proporem novas soluções.

"Criança de risco" é a expressão utilizada para denominar aquelas crianças que, embora muito novas para se concluir o diagnóstico, apresentam muitos sinais indicativos da dislexia. Existem muitos sinais de risco em crianças inseridas na Educação Infantil, que podem ou não levar à confirmação do diagnóstico de dislexia anos mais tarde (Andrade, Prado, \& Capellini, 2011).

Os sinais existentes antes dos oito anos, destacados por Luca e Nico (2018), que podem auxiliar o professor na identificação de um aluno de risco são: “[...] atraso na fala, dificuldade em aprender o nome das letras, dificuldade no reconhecimento de rimas e nas habilidades fonológicas, além do histórico familiar." (s/p).

É muito importante que crianças de risco para o desenvolvimento da dislexia sejam identificadas e trabalhadas com o estabelecimento de consciência fonológica, a principal dificuldade do disléxico na alfabetização (Silva \& Capellini, 2015; Mayeda, Navatta, \& Miotto, 2018). Não é necessário e não é indicado esperar pelo diagnóstico oficial - que só irá ocorrer por volta do final do segundo ano fundamental - para só então iniciar um atendimento que se destinará a contornar dificuldades de aprendizagem, entre outras dificuldades associadas ao longo do processo de escolarização. De acordo com a Comunidade Aprender Criança e o Instituto Glia (2014), o professor deve prover, desde a Educação Infantil, a estimulação de competências metalinguísticas como a consciência fonológica, a consciência sintática, a consciência morfológica e a consciência metatextual em crianças de risco para Dislexia (p. 25).

Já que não são público alvo da educação especial, para que esses alunos tenham o seu direito à educação garantido, os profissionais que os atendem em escolas regulares de ensino devem ter conhecimento sobre o transtorno, sobre as metodologias apropriadas, sobre a necessidade de construção de um PEI/PDI que contenha as adaptações curriculares necessárias para que, utilizando metodologias apropriadas, a criança disléxica possa aprender (Redig, Mascaro, \& Dutra, 2017). 
A dislexia em nada tem a ver com a falta de inteligência ou desejo de aprender, ao contrário do que o senso comum propaga e defende. A existência de inteligência normal ou superior é o principal critério diferencial de diagnóstico entre dislexia e deficiência intelectual. E o diagnóstico correto é fundamental para uma intervenção adequada. Com a metodologia apropriada, proposta especificamente para as suas dificuldades, o aluno com dislexia pode se desenvolver. Os métodos de ensino de leitura que, segundo pesquisas científicas controladas, demonstram maior eficácia, tanto para disléxicos quanto para crianças neurotípicas, são os fonológicos, haja vista possibilitarem ao disléxico (e a qualquer outra criança) efetuar a conexão grafema-fonema, sua principal dificuldade em idade escolar. Infelizmente, é um método que, apesar de largamente utilizado no mundo todo na atualidade, incluindo todos os países de primeiro mundo, é raramente utilizado no Brasil. Os dois únicos países que persistem utilizando-se em larga escala de métodos ineficazes para a alfabetização, e que evidenciam a dislexia em particular, são o Brasil e o México (Seabra \& Dias, 2011; Muszkat \& Rizzutti, 2012; Seabra \& Capovilla, 2016; Luca \& Nico, 2018; Rodrigues, 2018, Mayeda, Navatta \& Miotto, 2018).

\section{Intervenção pedagógica para o aluno disléxico}

Com base na leitura do conjunto de artigos, manuais, livros e capítulos de livros lidos sobre o assunto e referenciados ao final deste ensaio, efetuaremos indicações de algumas das principais intervenções pedagógicas a serem oferecidas ao aluno disléxico nesta seção do trabalho. Tais indicações estão concentradas principalmente em métodos de alfabetização apropriados, bem como na confecção e na aplicação de provas/avaliações.

Conforme já mencionado, em um ensino inclusivo, fazem-se necessárias adaptações curriculares (de objetivos, procedimentos, de metodologias, de materiais etc.), em sala de aula regular, a depender de cada caso, para alunos com NEEs, sejam portadores de laudos médicos ou não. Para atender às NEEs de alunos com dislexia, são necessárias algumas adaptações curriculares, principalmente em estratégias de ensino, em procedimentos e em avaliações. Para o aluno disléxico, adaptações curriculares de pequeno porte são as mais indicadas, viabilizando seu processo de ensino-aprendizagem e envolvendo modificações que são de responsabilidade do professor de sala de aula regular, se possível com ajuda de um professor de reforço ou auxiliar. Não há necessidade de encaminhando do aluno disléxico para sala de recursos.

Apesar das adaptações indicadas serem de pequeno porte, as adaptações de objetivos e de conteúdos (apesar de serem referidas pela literatura como adaptações de grande porte) 
também podem ser realizadas para tais alunos (Sousa, 2018). A definição dos objetivos alia-se à definição de critérios de desempenho quem por sua vez, verificam o cumprimento dos objetivos, considerando que é a partir dessa definição que se poderá avaliar o aluno e o próprio processo de ensino aprendizagem (Rodrigues, 2015).

Segundo autores como Sousa (2018), Poker et al. (2013), Redig, Mascaro, \& Dutra (2017) alunos com NEEs (dentre eles os disléxicos) necessitam da confecção de um PEI ou PDI para acompanhamento individual, sob pena de terem sua vida escolar prejudicada. Esse plano ampara o professor no processo de intervenção pedagógica, auxiliando a identificação das dificuldades dos alunos, a frequência dessas dificuldades, atentando ao que o aluno sabe ou não fazer, seus conhecimentos prévios, para que possam ser estabelecidos os objetivos intermediários e finais. Em seguida, definem-se a metodologia a ser utilizada, os materiais/recursos, os procedimentos e o programa de ensino propriamente dito. Nesse processo, é muito importante conhecer a criança, saber dos seus gostos para identificar reforçadores, como é a sua família e a sua vivência na sociedade. Conhecendo o aluno, as possibilidades de trabalho se abrem em um leque muito maior.

Ressalte-se que a partir da legislação inclusiva e o PDI previsto nos parâmetros curriculares nacionais, ambos já apresentados, conclui-se que a avaliação dos alunos disléxicos deve ser realizada de maneira diferenciada, já que esse pode ter habilidades linguísticas limitadas (no caso do aluno jovem, pode não ser de todo alfabetizado). A avaliação é parte constitutiva do processo de ensino e contribui para que o professor tenha noção de como está o aprendizado do aluno, prezando sempre pelo aprendizado, partindo dos objetivos previamente definidos e dos critérios de desempenho estabelecidos (Rodrigues \& Janke, 2014). A avaliação do aluno disléxico constitui-se em uma das principais adaptações procedimentais a serem implementadas. A avaliação também serve de parâmetro para avaliar o andamento do próprio PDI criado pelo professor, e sempre renová-lo. Pelo desempenho do aluno (mais fácil ou mais difícil atingir os critérios pré-estabelecidos) é possível dizer se o plano está sendo eficiente em cumprir as metas que são traçadas, e a depender do resultado haverá ou não necessidade de alteração do plano, mantendo-o atualizado e eficiente.

Os PEIs/PDIs devem ser arquivados no histórico escolar do aluno, acompanhando-o por toda a sua vida escolar, nas mudanças de série, nas transferências, mudanças de escola, de cidade, do ensino particular para o público ou vice-versa. $\mathrm{O}$ acompanhamento dos alunos com NEEs é imprescindível, pois cada novo(a) professor(a) pode conhecer detalhada e 
particularizadamente a vida escolar pregressa de seu aluno (Frank, 2003; Estill \& Pavão, 2017; Sousa, 2018).

A avaliação lida e escrita individualmente não é e nem deve ser a única maneira de se avaliar o aluno disléxico, porque ele obviamente tem dificuldade com as habilidades envolvidas nas avaliações escritas (leitura de enunciados e redação de textos, habilidades envolvidas em tais avaliações embora tenha conhecimentos sobre o conteúdo avaliado). $\mathrm{O}$ aluno com dislexia deve ser avaliado de modo alternativo, com procedimentos e critérios de correção diferenciados, de diversas maneiras, não apenas escrita, pois só assim o professor poderá observar seu verdadeiro avanço. Se o aluno disléxico tem dificuldades e/ou ainda não está alfabetizado, recomenda-se que sua avaliação seja realizada oralmente. É muito importante efetuar a investigação oral das respostas escritas confusas ou mesmo, a depender do caso, avaliação oral completa (Muszkat \& Rizzutti, 2012; Rodrigues \& Ciasca, 2016; Crenitte, Costa \& Freire, 2017).

Segundo Luca e Nico (2018), Crenitte, Costa e Freire (2017) e Estill e Pavão (2017), é fundamental ler o enunciado das questões para o aluno, quantas vezes for necessário, mudando o ritmo da leitura para haver compreensão, ou seja, é preciso certificar-se de que o aluno entendeu o que o enunciado está solicitando (não basta ler a prova inteira em voz alta para a sala toda e perguntar no geral se todos compreenderam o que se espera que seja feito). Além disso, a arguição oral sempre deve ser realizada para investigação de respostas escritas confusas, especialmente se as provas não forem realizadas de modo oral completo.

Segundo Borba e Braggio (2016) o adequado é que as provas sejam realizadas em uma sala separada e silenciosa, com ledor e tempo a mais para realização, de modo a não atrapalhar o ritmo dos demais e não favorecer a ocorrência de bullying. Se possível, as avaliações devem ser feitas com maior frequência de modo a reduzir a quantidade de conteúdo a ser estudado, o que favorece a memorização, a organização e o entendimento do conteúdo em estudo. Ao aluno disléxico deve ser permitida a utilização de tabuada impressa (após ter entendido o processo da multiplicação), calculadora (no ensino médio) e fórmulas. Eventualmente, poderão ser realizadas avaliações por outros meios que não provas, como trabalhos, expressão artística etc.

Borba e Braggio (2016) oferecem uma série de dicas práticas, as quais recomendamos a leitura, destinadas a minimizar a dificuldade do disléxico a entender o que lê, especialmente em situação de prova. Várias das orientações de Borba e Braggio (2016) são encaminhamentos metodológicos relacionados à dificuldade que o disléxico tem com o processamento e a memória visual e/ou auditiva (que lhe impede ou dificulta a automatização da leitura e da 
escrita). Por conta disso, é importante repetir o enunciado das atividades e das provas sempre que necessário; ou não elaborar avaliações que privilegiem a memorização de nomes, datas, fórmulas, regras gramaticais, espécies, definições etc. Borba e Braggio (2016), Rodrigues e Ciasca (2016), Estill e Pavão (2017), Crenitte, Costa e Freire. (2017) recomendam que, quando tais informações forem importantes, podem ser fornecidas ao aluno verbalmente ou por escrito para que ele possa utilizá-las na resolução da questão. Pela mesma razão, é importante privilegiar a avaliação de conceitos e de habilidades e não de definições, bem como se sugere a permissão à utilização da tabuada, da calculadora, de gravador, de anotações, de dicionários e outros registros durante as avaliações. Também pela memorização prejudicada é importante que se ofereçam instruções curtas e simples (uma de cada vez).

Tanto o aluno disléxico quanto alunos com outras dificuldades de aprendizagem tendem a ser lentos. Essa é a razão pela qual autores como Luca e Nico (2018), Borba e Braggio (2016) e a Comunidade Aprender Criança/Instituto Glia (2014) sugerem que se ofereça mais tempo para que realizem provas e atividades mais complexas, que se ofereça a possibilidade de realização de prova em outro local que não a sala de aula e que se elaborem mais avaliações com menos conteúdo. A realização de provas em outros locais também evita o bullying a que esses alunos estão sujeitos pelas características oralizadas de suas avaliações, além da lentidão característica.

Quanto aos critérios de correção das provas, Estill e Pavão (2017), Crenitte, Costa e Freire (2017), Luca e Nico (2018) e a Comunidade Aprender Criança/Instituto Glia (2014) recomendam que o professor não desconte pontos por erros de escrita relacionados ao transtorno, especialmente se a prova em questão não for de Língua Portuguesa, valorizando os aspectos qualitativos ao invés de quantitativos, priorizando seu progresso individual. Em outras palavras, o docente não deve se ater somente às falhas, mas valorizar os acertos e as boas ideias. Ademais, é importante não solicitar respostas iguais ao livro, mas fomentar respostas interpretativas, pois os disléxicos têm dificuldade para decorar.

No que diz respeito à confecção de provas (e também atividades), recomenda-se evitar "pegadinhas", textos confusos ou enunciados muito longos. Por isso, é importante tratar de um assunto de cada vez e dividir um texto grande em textos menores, destacando os períodos e compreendendo-os um a um. Além disso, é fundamental utilizar sempre uma única fonte, preferencialmente Arial ou Times New Roman, tamanho 12 a 14, espaço 1,5 ou 2,0. Não se deve misturar fontes e nem utilizar itálico ou outras fontes manuscritas (Luca \& Nico, 2018; Borba \& Braggio, 2016). Ainda sobre confecção de provas, Borba e Braggio (2016) 
recomendam que se ofereçam folhas limpas, sem rasuras e sinais que possam confundir o leitor, além de vários cuidados relacionados à construção de questões de falso-verdadeiro, como evitar o uso de afirmações negativas, de expressões absolutas. Sugere-se a construção de afirmações claras e com extensão aproximada, inclusão de apenas um argumento ou ideia em cada afirmação.

Ao formular questões de associação, Borba e Braggio (2016) orientam que se trate um assunto de cada vez e que se redijam com cuidado os itens. Sugerem ainda que não se utilize mais de um "claro" em cada sentença (a não repetição de palavras diríamos que poderia ser uma regra para a elegância de qualquer sentença). Pedem ainda que a lacuna correspondente às palavras ou expressões significativas envolvam conhecimentos ou conceitos básicos e essenciais ao invés de detalhes secundários. No tocante à formulação de questões de lacuna, os autores incentivam que se conserve a terminologia do material adotado pela escola ou do registro efetuado em sala.

Quanto à dificuldade do disléxico em se reconhecer e se orientar no espaço visual, Borba e Braggio (2016) orientam para que observemos as direções da escrita no corpo da avaliação (esquerda para a direita e de cima para baixo). Borba e Braggio (2016), Crenitte, Costa e Freire (2017), Estill e Pavão (2017) recomendam também nunca fechar uma nota sem esclarecer com o aluno o conteúdo de uma resposta escrita confusa, retomando a prova com o aluno e verificando, oralmente, o que ele quis dizer com o que escreveu, pesquisando a natureza dos erros cometidos. É importante saber se não houve compreensão do enunciado ou se houve compreensão e não houve apreensão do conteúdo (não soube aplicar o conceito ou a fórmula). A expressão oral é muito importante para o disléxico e ele deve poder comunicar o que sabe, propondo problemas e apresentando soluções de forma oral e não apenas pela leitura e escrita. Do contrário, estaremos lhe negando um direito fundamental de livre expressão.

\section{Considerações Finais}

Pôde-se perceber que, para haver intervenção apropriada, o aluno com dislexia deve ser identificado e ter as suas NEEs atendidas com maior rapidez pelas escolas, além do professor estar preparado para implementar as intervenções pedagógicas necessárias. A legislação brasileira já é inclusiva e prevê educação com qualidade para todos, garantindo não apenas o acesso, mas a permanência na escola; porém, por alguma razão, isso não é cumprido, o que gera a necessidade da criação de uma quantidade cada vez maior de leis, com maiores especificidades para que se tente fazer com que a constituição, lei maior e que preconiza a 
inclusão de todos, seja cumprida. Acreditamos que não deveria ser necessária a criação de uma nova lei para que o aluno disléxico fosse incluído, mas sim que as leis já existentes fossem efetivamente cumpridas. No entanto, caso o projeto de Lei $\mathrm{n}^{0} 7.081 / 2010$, específico para Dislexia e TDAH, seja aprovado, os professores poderão ter mais uma oportunidade para atentar aos alunos com essas características e conhecer mais sobre os transtornos específicos de aprendizagem (bem como sobre TDAH).

Logo, todos, ao contrário do que se vê, deveriam ser acompanhados, independentemente da existência de diagnóstico ou do tipo de diagnóstico, sem a necessidade de uma nova lei de educação especial e/ou inclusiva para garantir que as escolas cumpram o que se espera do seu papel: garantir a todos o acesso e a permanência na escola e a conclusão dos ciclos de escolarização com ensino adaptado às suas necessidades. O acompanhamento de nossos estudantes com NEEs, sejam quais forem, já deveria acontecer em todas as escolas, realizado por meio de uma equipe multi e interdisciplinar.

Compreendemos também que a dislexia existe e que os alunos disléxicos estão na escola, necessitando de atendimento e não de negação de suas NEEs, de abandono, de constrangimento, de preconceito e de bullying. Não se deve (por questões éticas ou legais) deixar um aluno de lado devido às suas dificuldades de aprendizagem, sejam elas quais forem, ou por não saber como lidar com a situação de um aluno em particular, muito embora essa seja uma realidade presente em muitos casos, principalmente nas escolas particulares (embora não exclusivamente). O preparo que não temos hoje podemos alcançá-lo amanhã, e o aluno que não temos hoje teremos amanhã. Note-se que a concepção de inclusão adotada pelas autoras deste trabalho e que encontra suporte na legislação inclusiva nacional é a que prevê o ensino efetivo e não apenas a socialização do aluno, muito embora a concepção predominante nas escolas brasileiras pareça ser a última.

Defendemos que o PEI/PDI do aluno disléxico pode e deve ser feito pelo professor de sala de aula regular, com ajuda do coordenador pedagógico, se assim o desejar. O PEI/PDI não é instrumento de uso exclusivo do AEE na educação especial. O professor de sala de aula regular que conhece bem o seu aluno e os conteúdos a oferecer e a avaliar pode e deve construir um PEI/PDI nos mesmos moldes expostos pela literatura, indo desde o conhecimento do repertório de entrada do aluno até a avaliação, em consonância com os objetivos adequados ao planejamento a ele ofertado. No caso do aluno disléxico, um PEI baseado em adaptações curriculares de "pequeno porte", mas de grande alcance. 
Verificamos a ausência da utilização de uma metodologia eficaz à disposição dos educadores, utilizada no mundo todo, com eficácia garantida por evidências científicas e que se mostre favorável à utilização também por crianças neurotípicas (além das disléxicas). Ainda que esses métodos (fonológicos) estejam à disposição, o Brasil ainda opta por métodos cuja eficácia evidencia a dificuldade das crianças disléxicas e provoca dificuldades até mesmo em crianças "normais", pela sua ineficácia

\section{Referências bibliográficas}

Associação Brasileira de Dislexia - ABD - (2018). Estatísticas 2013-2018. Recuperado em 26 março 2020 de http://www.dislexia.org.br/estatisticas-2013-2018/.

American Psychiatric Association - APA - (2014). APA Manual Diagnóstico e Estatístico de Transtornos Mentais: DSM - 5. (5a. ed.) Porto Alegre: Artmed.

Andrade, O. V. C. dos A., Prado, P. S. T. do, \& Capellini, S. A. (2011). Desenvolvimento de ferramentas pedagógicas para identificação de escolares de risco para a dislexia. Revista Psicopedagogia, 28(85). Recuperado em 15 de fevereiro de 2020 de http://hdl.handle.net/11449/117867.

Barbosa, T., Rodrigues, C. C., Toledo-Piza, C. M., Navas, A. L. G. P., \& Bueno, O. F. A. (2015). Perfil de linguagem e funções cognitivas em crianças com dislexia falantes do Português Brasileiro. CoDAS, 27(6), 565-574. https://doi.org/10.1590/2317$\underline{1782 / 20152015043}$

Borba, A. L., \& Braggio, M. A. (2016). Como interagir com o disléxico em sala de aula. São Paulo: ABD (Associação Brasileira De Dislexia). Recuperado em 15 de fevereiro de 2020 de http://www.dislexia.org.br/como-interagir-com-o-dislexico-em-sala-de-aula/.

Capellini, S. A., Germano, G. D., \& Cardoso, A. C. V. (2008). Relação entre habilidades auditivas e fonológicas em crianças com dislexia do desenvolvimento. Psicologia Escolar e Educacional, 12(1), 235-251. https://doi.org/10.1590/S1413-85572008000100016

Comunidade Aprender Criança/Instituto Glia (2014). Cartilha da Inclusão Escolar: Inclusão baseada em evidências científicas. Instituto Glia. Recuperado em 15 de fevereiro de 2020 de https://www.aprendercrianca.com.br/cartilha-da-inclusao/385-cartilha-da-inclusao-.

Constituição da República Federativa do Brasil (1988). Brasília, DF. Recuperado em 18 maio 2018 https://www2.senado.leg.br/bdsf/bitstream/handle/id/518231/CF88_Livro_EC91_2016.pdf.

Crenitte, P. A. P., Costa, A. R. A. da, \& Freire, T. (2017). Atuação fonoaudiológica nos Transtornos Específicos de Aprendizagem: experiência da FOB/USP no diagnóstico, intervenção e orientações aos professores e pais. In: Navas, A. L., Azoni, C. S., Oliveira, D. G. de, Borges, J. P. A., Mousinho, R. (Orgs). Guia de boas práticas: do diagnóstico à intervenção de pessoas com transtornos especificos de aprendizagem (pp. 49-54). São Paulo: Instituto ABCD. Recuperado em 18 maio 2018 de https://www.institutoabcd.org.br/guia-de-boas-praticas/.

Dutra, C. P., Santos, M. C. D. dos, \& Guedes, M. T. (2010). Manual de Orientação: Programa de Implantação de Sala de Recursos Multifuncionais. Secretaria de Educação Especial/SEESP. Recuperado em 30 novembro 2018 de http://portal.mec.gov.br/index.php?option $=$ com_docman \&view $=$ download\&alias $=9936-$ manual-orientacao-programa-implantacao-salas-recursos-multifuncionais\&Itemid=30192. 
Estill, C. A., \& Pavão, V. (2017). AND: Transtornos de Aprendizagem - A Formação e Intervenção do Professor. In: Navas, A. L., Azoni, C. S., Oliveira, D. G. de, Borges, J. P. A., Mousinho, R. (Orgs). Guia de boas práticas: do diagnóstico à intervenção de pessoas com transtornos especificos de aprendizagem (pp. 22-24). São Paulo: Instituto ABCD. Recuperado em 18 maio 2018 de https://www.institutoabcd.org.br/guia-de-boas-praticas/.

Fonseca, M. F. (2017). Consciência fonológica e o ensino de leitura: quando começar?. Revista Linguística, 13(1), 86-103. Recuperado em 24 de março de 2020 de https://revistas.ufrj.br/index.php/rl/article/view/10422/7914.

Frank, R. (2003). A vida secreta da criança com dislexia. São Paulo: M. Books do Brasil.

Heredero, E. S. (2010). A escola inclusiva e estratégias para fazer frente a ela: as adaptações $\begin{array}{llll}\text { curriculares. Acta Scientiarum } \quad \text { Education, } & \text { 32(2), }\end{array}$ https://doi.org/10.4025/actascieduc.v32i2.9772.

International Dyslexia Association - IDA - (2002). IDA Definition of dyslexia. Baltimore. Recuperado em 18 maio 2018 de http://ma.dyslexiaida.org/wpcontent/uploads/sites/7/2016/03/Definition_of_Dyslexia.pdf.

International Dyslexia Association - IDA - (2017). IDA Dyslexia in the classroom What every teacher needs to know. Baltimore. Recuperado em 18 maio 2018 de https://dyslexiaida.org/wp-content/uploads/2015/01/DITC-Handbook.pdf.

Lei $n^{\circ} 8.069$, de 13 de julho de 1990. Estabelece o Estatuto da Criança e do Adolescente (ECA). Brasília, DF. Recuperado em 17 setembro 2018 de https://presrepublica.jusbrasil.com.br/legislacao/91764/estatuto-da-crianca-e-doadolescente-lei-8069-90\#art-53.

Lei $n^{\circ}$ 3.934, de 20 de dezembro de 1996. Estabelece a Lei de Diretrizes e Bases da Educação. Brasília, DF. Recuperado em 25 maio 2018 de http://www.2senado.leg.br/bdsf/bitstream/handle/id/529732/lei de diretrizes_e bases_led. pdf.

Lei $n^{\circ}$ 13.005, de 25 junho de 2014. Plano Nacional de Educação (2014- 2024). Diário Oficial da União, Brasília, DF. Recuperado em 09 novembro 2018, de http://portal.mec.gov.br/seesp/arquivos/pdf/plano1.pdf.

Leite, L. P. (2008). Práticas Educativas: adaptações curriculares. Bauru: MEX/FC/SEE.

Lemos, J. (2016). Dislexia: É preciso entender e intervir neste transtorno de aprendizagem. Khóra: Revista Transdisciplinar, 3(4). Recuperado em 15 de fevereiro de $2020 \mathrm{de}$ http://www.site.feuc.br/khora/index.php/vol/article/view/80.

Lima, R. F. de, Salgado, C. A., \& Ciasca, S. M. (2008). Desempenho neuropsicológico e fonoaudiológico de crianças com dislexia do desenvolvimento. Revista Psicopedagogia, 25(78), 226-235. Recuperado em 15 de fevereiro de 2020 de http://pepsic.bvsalud.org/scielo.php?script $=$ sci arttext\&pid $=\mathrm{S} 0103-$ $\underline{84862008000300005 \& \operatorname{lng}=p t \& t \operatorname{lng}=\mathrm{pt} .}$

Luca, M. I. O., \& Nico, M. A. N. (2018). Dislexia: da família à Escola. Curso Associação Brasileira de Dislexia (ABD), não publicado.

Mayeda, G. B. G., Navatta, A. C. R., \& Miotto, E. C. (2018). Intervenção fonológica em escolares de risco para dislexia: revisão de literatura. Revista Psicopedagogia, 35(107), 231241. Recuperado em 23 de março de 2020 de http://pepsic.bvsalud.org/scielo.php?script=sci arttext\&pid=S0103-84862018000200010.

Matta, C. G. S. da, Perrut, R. M. P, \& Alcântara, E. F. S. de. (2017). Dislexia: Uma Maneira Diferente de Aprender. Episteme Transversalis, 8(2), 52-63. Recuperado em 23 de março de $2020 \mathrm{de}$ http://revista.ugb.edu.br/ojs302/index.php/episteme/article/view/870. 
Muszkat, M., \& Rizzutti, S. (2012). O professor e a dislexia. São Paulo: Cortez.

Parâmetros curriculares nacionais: Adaptações curriculares (1998). Secretaria de Educação Fundamental e Secretaria de Educação Especial. Brasília: MEC/SEF/SEESP.

Poker, R. B., Martins, S. E. S. de O., Oliveira, A. A. S. de, Milanez, S. G. C., \& Girotto, C. R. M. (2013). Plano de Desenvolvimento Individual para o Atendimento Educacional Especializado. São Paulo: Cultura Acadêmica e Marília: Oficina Universitária.

Projeto de Lei 7081/2010. Dispõe sobre o diagnóstico e o tratamento da dislexia e do Transtorno do Déficit de Atenção com Hiperatividade na educação básica. Recuperado em 20 agosto 2018

http://www.camara.gov.br/proposicoesWeb/fichadetramitacao?idProposicao $=472404$.

Redig, A. G., Mascaro, C. A. A. de C., \& Dutra (2017). A formação continuada do professor para a inclusão e o plano educacional individualizado: uma estratégia formativa? Revista Diálogos e Perspectivas em Educação Especial, 4(1), 33-44. https://doi.org/10.36311/23588845.2018.v4n1.04.p33.

Resolução $C N E / C E B n^{\circ} 2$ (2001). Diretrizes Nacionais para a Educação Especial na Educação Básica. Brasília, DF: Ministério da Educação, Secretaria de Educação Especial. Recuperado em 21 julho 2018 de http://portal.mec.gov.br/seesp/arquivos/pdf/diretrizes.pdf.

Rodrigues, M. E., \& Janke, J. C. (2014). O Papel do Professor na proposta da Análise do Comportamento. Faz Ciência, 16(23). Recuperado 15 de fevereiro de 2020 de http://erevista.unioeste.br/index.php/fazciencia/article/view/10917.

Rodrigues, M. E. (2015). Problemas de Aprendizagem: Métodos de Pesquisa e Intervenção. Anais do XII CONPE - Congresso Nacional de Psicologia Escolar e Educacional (p. 809). São Paulo: ABRAPEE e 37tf Annual Conference ISPA.

Rodrigues, S. das D., \& Ciasca, S. M. (2016). Dislexia na escola: identificação e possibilidades de intervenção. Revista Psicopedagogia, 33(100), 86-97. Recuperado em 15 de fevereiro de 2020 de http://pepsic.bvsalud.org/scielo.php?script=sci_arttext\&pid=S0103$\underline{84862016000100010 \& \operatorname{lng}=\mathrm{pt} \& \mathrm{t} \operatorname{lng}=\mathrm{pt} .}$

Rodrigues, M. E. (2018). Dislexia: Transtorno específico de aprendizagem com prejuízo na leitura, não publicado.

Seabra, A. G., \& Dias, N. M. (2011). Métodos de alfabetização: delimitação de procedimentos e considerações para uma prática eficaz. Revista Psicopedagogia, 28(87), 306-320. $\begin{array}{llllll}\text { Recuperado em } & 15 & \text { de } & \text { fevereiro de } & 2020 & \text { de }\end{array}$ http://pepsic.bvsalud.org/scielo.php?script $=$ sci_arttext\&pid=S0103$\underline{84862011000300011 \& \operatorname{lng}=\text { pt\&tlng }=\text { pt. }}$.

Seabra, A. G., \& Capovilla, F. C. (2016). Alfabetização Fônica: construindo competência de leitura e escrita: livro do aluno. 4. Ed. São Paulo: Casa do Psicólogo.

Silva, C. da, \& Capellini, S. A. (2015). Eficácia de um programa de intervenção fonológica em escolares de risco para a dislexia. Revista CEFAC, 17(6), 1827-1837. https://doi.org/10.1590/1982-021620151760215.

Sousa, S. L. de. (2018). Transtornos Aprendizagem: direitos e deveres - Curso ABD, não publicado.

United Nations Children's Fund (UNICEF) (1990). Declaração Mundial sobre Educação para Todos: Conferência de Jomtien. Jomtien. Recuperado em 20 setembro 2018 de https://www.unicef.org/brazil/pt/resources 10230.htm.

United Nations Educational, Scientific and Cultural Organization (UNESCO) (1994). Declaração De Salamanca e Enquadramento da Ação na área da Necessidades Educativas Especiais. Lisboa. Recuperado em 28 maio 2018 de http://portal.mec.gov.br/seesp/arquivos/pdf/salamanca.pdf. 